\title{
Methane release analysis on gas hydrate at the Okhotsk Sea slope based on SONIC technology
}

\author{
Hechao Zang ${ }^{1,2, a}$, Zhili Hua ${ }^{1,2, b}$ and Bo Liü, 2, c \\ ${ }^{1}$ Institute of Oceanographic Instrumentation of Shandong Academy of Sciences, Shandong 266100, \\ China; \\ ${ }^{2}$ Shandong Provincial Key Laboratory of Ocean Environment Monitoring Technology, Shandong \\ 266100, China. \\ azanghechao@126.com, b455272587@qq.com, ${ }^{\text {c } 297523645 @ q q . c o m ~}$
}

Keywords: Sonic software, Okhotsk Sea, gas hydrate.

\begin{abstract}
This paper studies the case of the methane release of the Okhotsk Sea slope, It is made a large scale acoustic sweep focusing on the east slope of Sakhalin Island based self-developed software SONIC. Detecting and judging the location of undersea methane gas leaks (GF),reisen and seabed, surveying morphological changes of methane release point with collecting the echo signal and visualization fuctions of SONIC software. By the use of GPS system for real-time tracking and positioning, it is successfully collected core samples of gas hydrate in various area with gravity sampler and other sampling tool. The samples were analyzed in time, evaluated the amount of methane emission and depositing in the area and other kinds of data, provided useful information to analyze the causes of this region's gas hydrate depositing and mining.
\end{abstract}

\section{Introduction}

Combustible ice ${ }^{[1,2]}$ (also known as gas hydrate) is a solid substance combined by the gas and water, has a unique cage structure, usually appear white ice-like appearance, it is also known as combustible ice. According to a rough estimation ${ }^{[3]}$, huge reserves of gas hydrate contained in superficial crust of the Earth, methane as the main component of the carbon content of gas hydrates is about 11000Gt $(1 \mathrm{Gt}=1015 \mathrm{~g})$, most of which exist in deep seabed, which reserves are approximately 100 times more than land reserves. Oil and coal is depleting resources today, so the exploration and development of gas hydrate become more and more important.

Gas hydrate is buried in the sea floor sediments, burial place must be determined by its specific symbols. Reisen is a water-gas (mainly in hydrocarbon gas) mixed seabed excretion phenomenon which causes of seismicity and instability of gas hydrate depositing structure ${ }^{[4]}$. When seismic activities and gas hydrate depositing structure collapse occurred, there will be natural gas spills eruption, formed reisen phenomenon.Reisen is an important symbol of finding gas hydrate deposits. 


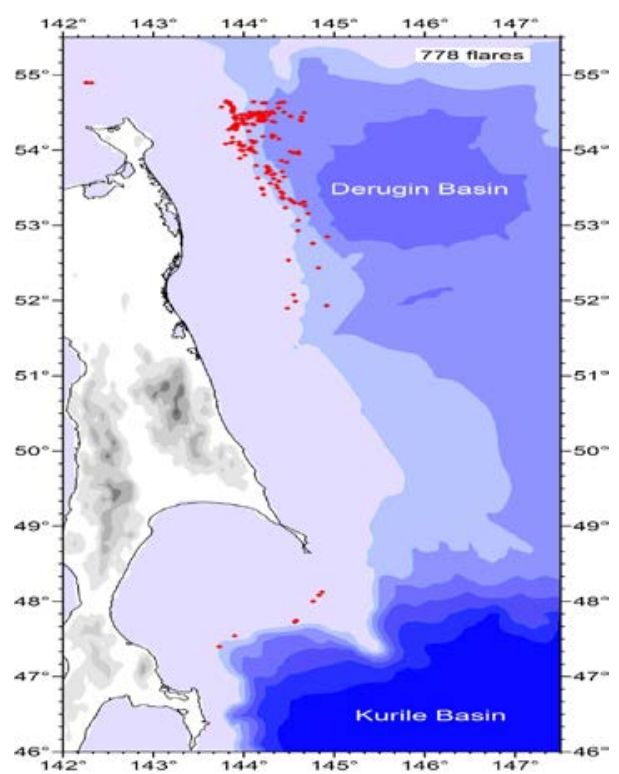

Fig. 1 GF of Okhotsk seas and cold seeps eruption points

In the process of China-Russian scientific investigation of Okhotsk Sea, through the use of self-developed PC software SONIC controling deep-sea exploration equipment -Echo underwater acoustic detection system, we found that many GF and reisen at eastern slope of HaSalin island in the Okhotsk Sea, see Figure 1. Red dots marked the GF points and reisen on the chart. Sonar and GPS located the position, gravity sampler and other sampling equipment successlly got the core samples of gas hydrate in sediment of seabed. This paper discusses how to use the SONIC software to find GF and reisen, analysis concentration and pressure parameter of the methane gas in reisen, finally get several conclusions.

\section{The Application of The SONIC Software}

To understand the application of the SONIC software,first of all ,we must know the running way of the whole Echo underwater acoustic detection system which is controled by the SONIC software,and we can realize the detail of visualization fuction of the SONIC.

\subsection{The Overall Structure of Underwater Acoustic System.}

The hydroacoustic observations were carried out using a hydroacoustic complex created on the bases of the upgraded ship'secho sounders Sargan-EM and ELAC,sonars Sargan-GM( see Figure 2) and multichannel digital registration of sonar echoes on four independent channels with frequencies of $12 \mathrm{kHz}, 20 \mathrm{kHz}$ and $135 \mathrm{kHz}$. At a time with acoustic measurements, accurate vessel's coordinates are estimated with the help of global positioning system (GPS), seabed depth signals, seabed topography signals and seabed profile analog signals could be transferred in time to the SONIC PC software, reducted and visualized by SONIC PC software, and finally displayed on two colorful screens, so that scientific investigators could realize the real-time situation of the methane bubbles of the GF and reisens. 


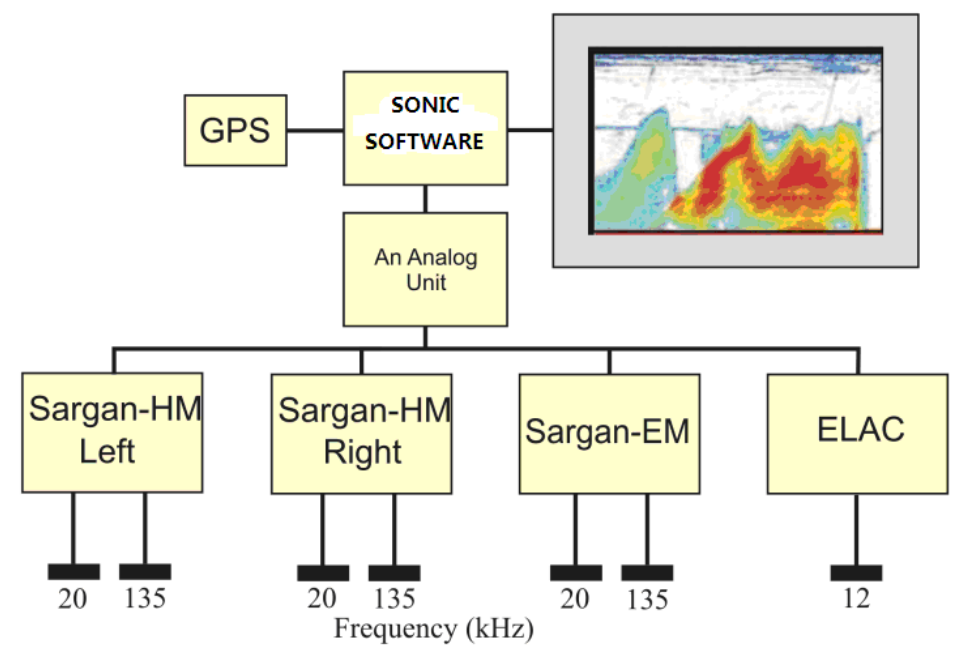

Fig. 2 The scheme of Echo sounder system structure

\subsection{SONIC Software.}

As the control part of the whole system, SONIC software is created based VB 6.0 software, consists of four parts of the parameters settings screen,the system control,the underwater acoustic signal processing and the hydroacoustic signal imaging. The SONIC software have the ability of dealing with the real-time underwater acoustic signal send by four underwater acoustic channels, have the functions of collection, pre-processing, storage the visualization.Its hardware configuration includes four parts:

1、 the interface unit;

2、 two sound cards Creative Labs;

3、 personal comprter(Pentium- II and higher);

4、 operation system Win32 type;

Echo-signals are converted to digital form with the help of four 16-bit analog-to-digital converters of sound cards; their synchronous detection and low frequency filtration are carried out further. The parameters of echo-signal registration(range of registered depths, mean sound speed etc.) are set by the program (see Figure 3) or with the help of initializing file.

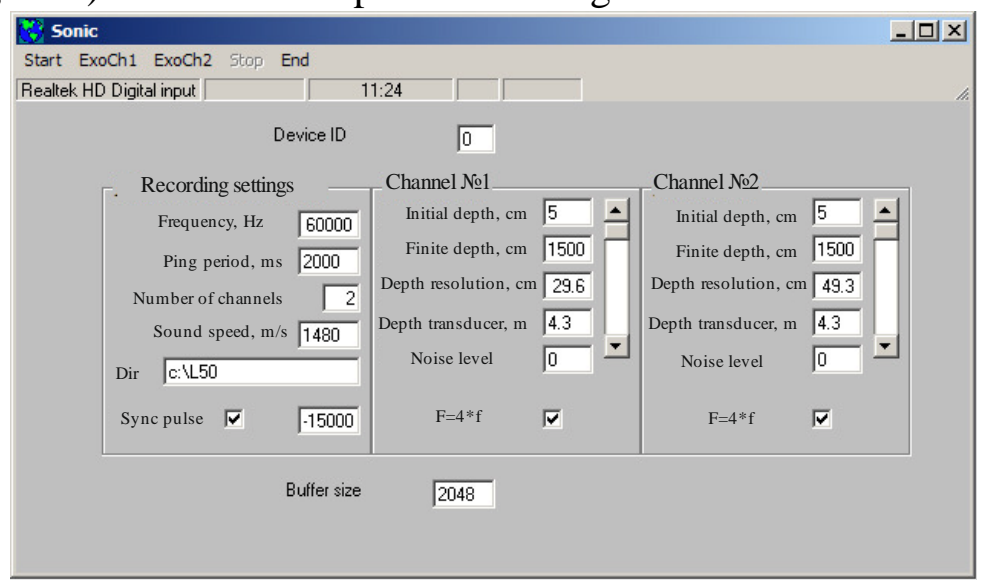

Fig. 3 SONIC initial dialog

The digitized echo-signals are recorded as data files on a hard disk of the computer. The dynamic range of a system exceeds $90 \mathrm{~dB}$.

Record format of echo-signals is following : first 8 bytes - date and time of eco sounder ping (type of variable-date of Visual Basic 6 system programming), further the values of echo-signals of given ping follow in the order of depth increase, with which they come. Each counting $(\mathrm{N})$ is equal to ratio of registered depth range to depth resolution, and therefore the record of one ping takes $8+2 \mathrm{~N}$ bytes. The name of a data file(in hours and minutes).For example, if the first echo-signal was sent by June 1,2010 at 2 hours 25 minutes, the data file is recorded under name 0225. 1dt or 0225.2dt, depending 
on channel numbers in a folder Data 1 Jun10 or Data1 $\backslash 1 \mathrm{Jun} 10$ depending on numbers of a sound card. Additionally, configuration file 0225.1cf or 0225.2cf is recorded in the same folders as initializing file (INI-file) with the necessary information about parameters of echo-signal registration(see Table 1).

Table 1 An Example of Configuration's File

\begin{tabular}{|c|c|c|c|c|c|}
\hline \multicolumn{6}{|c|}{ An Example of Configuration's File } \\
\hline $\begin{array}{l}\text { Parameter } \\
\text { class }\end{array}$ & Commen parameter set & $\begin{array}{l}\text { Echosounder } \\
\text { parameter set }\end{array}$ & $\begin{array}{c}\text { Sound card } \\
\text { parameter set }\end{array}$ & $\begin{array}{c}\text { Tunnel } \\
\text { parameter } \\
\text { set }\end{array}$ & Ver \\
\hline 1 & Date $=6 / 6 / 2010$ & $\begin{array}{l}\text { Working } \\
\text { frequency } \\
=19700 \mathrm{HZ}\end{array}$ & Device ID $=0$ & $\begin{array}{c}h(\text { begin })= \\
5 \mathrm{~m}\end{array}$ & $\begin{array}{c}\text { Ver=1.0.0. } \\
1\end{array}$ \\
\hline 2 & Time=2:07:36 & $\mathrm{hAnnt}=4.3 \mathrm{~m}$ & $\begin{array}{c}\text { Frequency = } \\
60000 \mathrm{HZ}\end{array}$ & $\begin{array}{l}h(\text { end })= \\
1500 \mathrm{~m}\end{array}$ & \\
\hline $\begin{array}{l}3 \\
4 \\
5 \\
6 \\
7 \\
8 \\
9 \\
10\end{array}$ & $\begin{array}{l}\text { Vessel } \\
\text { Name:Academic } \\
\text { M.A.Lavrentyev } \\
\text { Region= Okhotsk } \\
\text { Sea } \\
\text { nCh=1 } \\
\text { soundSpeed=1480 } \\
\text { Sound speed in } \\
\text { water, m/sec } \\
\text { Period=2000 } \\
\text { Period of ping,m/c } \\
\text { nF=1200 } \\
\text { Number of pings in } \\
\text { the file: } \\
\text { Dir=e: } \backslash \text { Lavr50 } 20-\mathrm{R}\end{array}$ & & $\mathrm{UMAX}=1$ & $\mathrm{~h}=29.6 \mathrm{~m}$ & \\
\hline
\end{tabular}

The visualization of SONIC software in real time is carried out using two standard colour monitors. Each channel is represented on the two multi-coloured echograms with independent range of depths and with independent colour palett(see Figure 4). The software provides synchronous detection , filtration , registration and visualization of an echo signal in the required range of depths.

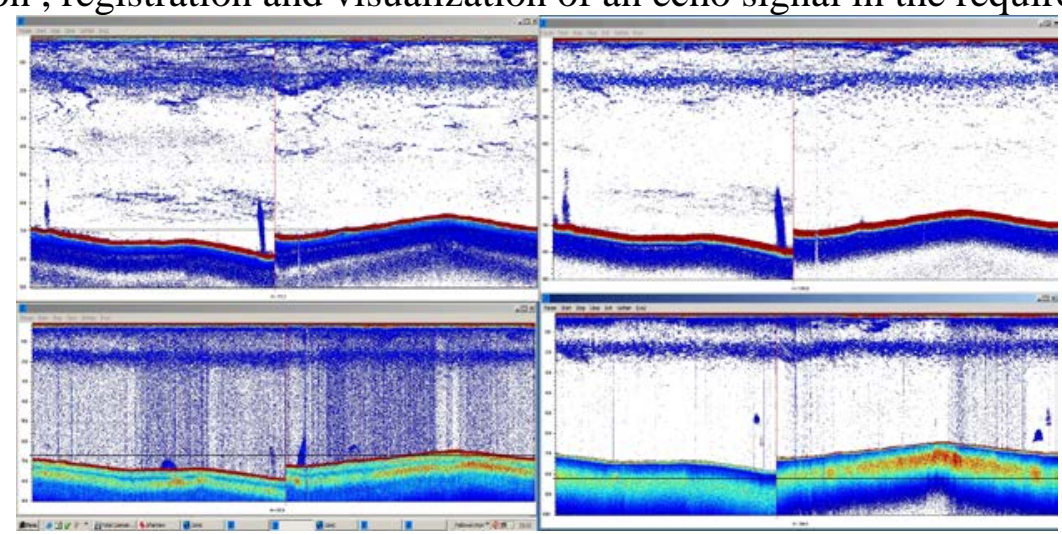

Fig. 4 The Acoustic Signals of Seabed

The SONIC software has two synchronization modes - internal and external. In a mode of internal synchronization all acoustic devices are managed by SONIC software. This mode is preferential, because it allows vary a frequency of ping. At an external synchronization mode one of echo sounders is master and it manages other devices and SONIC software. The external synchronization mode is enforced and it is applied in cases, when one of echo sounders does not support external trigger. In current cruise the mode of external synchronization was used. 


\section{The Analysis of The SONIC Software}

The following diagram (see Figure 5) as the expedition vessel at full speed mode, the application sounder Sargan-EM and ELAC are working with dual frequency (12 and 20kHz) acoustic signal acquisition in the vertical direction by SONIC software processing, and display the image on the color screen.

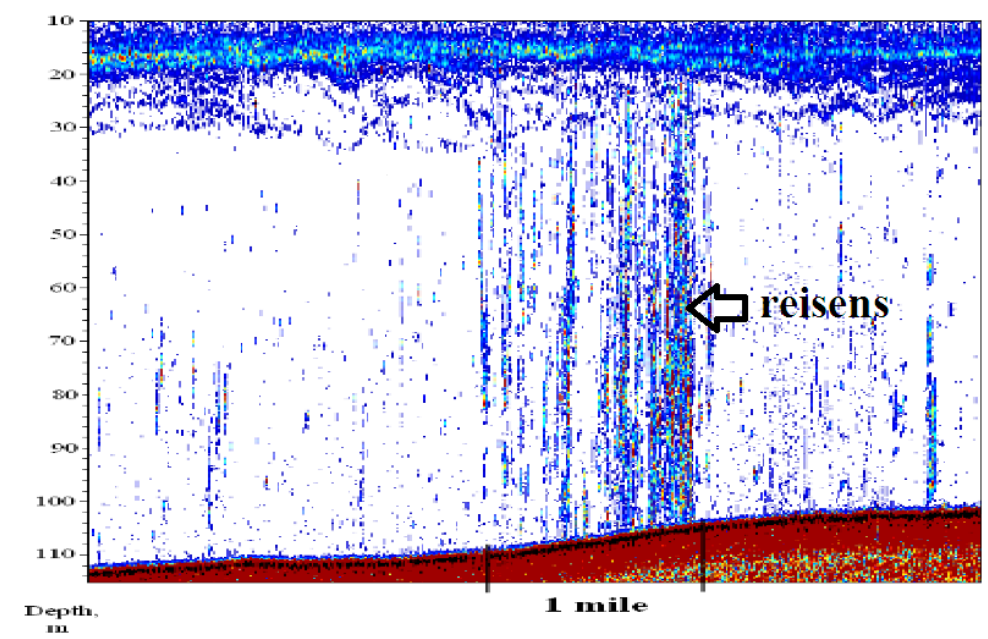

Fig. 5 Two or more references

The dense vertical signal which the arrows indicated in the figure is reisens ${ }^{[5]}$ jetting formation, in which the blue vertical line represents the rising water bubbles, finding reisens marks there are hydrocarbons gas lurking in seabed, it is an important indicator of gas hydrate found ${ }^{[6,7]}$. After reisens found,it will use the gravity sampler to get the core samples immediately, the core samples obtains sediment cores (Figure 6 Left Figure) contain gas hydrate, and we successfully got the gas hydrate samples (Figure 6 Right Figure).

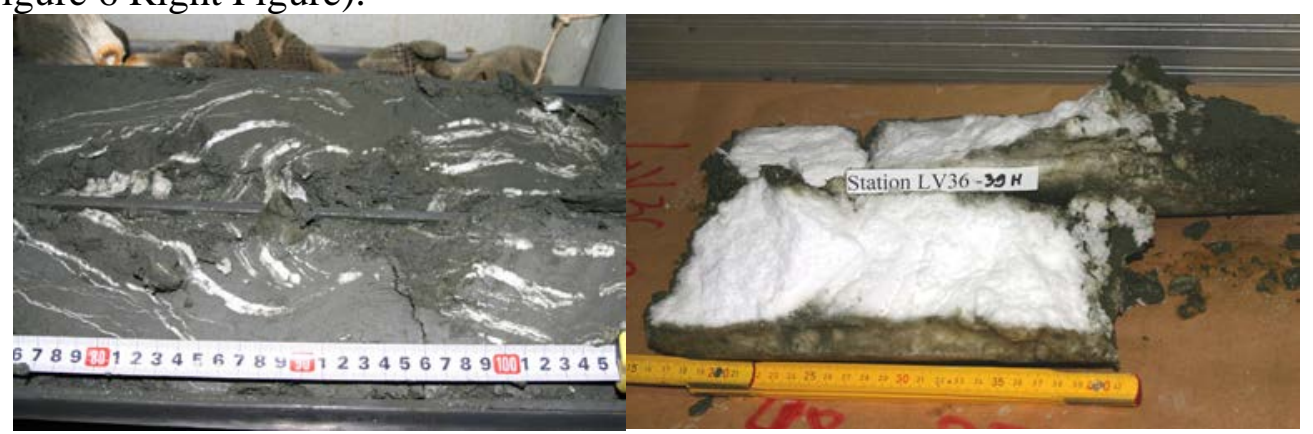

Fig. 6 The Gas Hydrate Samples

About 96 GF and reisens were found in this cruise, about 30 ones are first-time discovered, gas hydrate found in 18 sediment core samples, and analyzed chemical composition of methane content, sediment and pore water.

The following figure (see Figure 7) is 200m width GF spot dense regions of shallow slope seabed map ${ }^{[8]}$ imaged by SONIC software, you can see a large number of methane bubbles leak from the sea bed to form a reisen. The red area that arrow point out is a high concentration of methane gas signal, the GF point located on the shelf and shelf edge above the Methane Hydrate Stability Zone (MHSZ). 


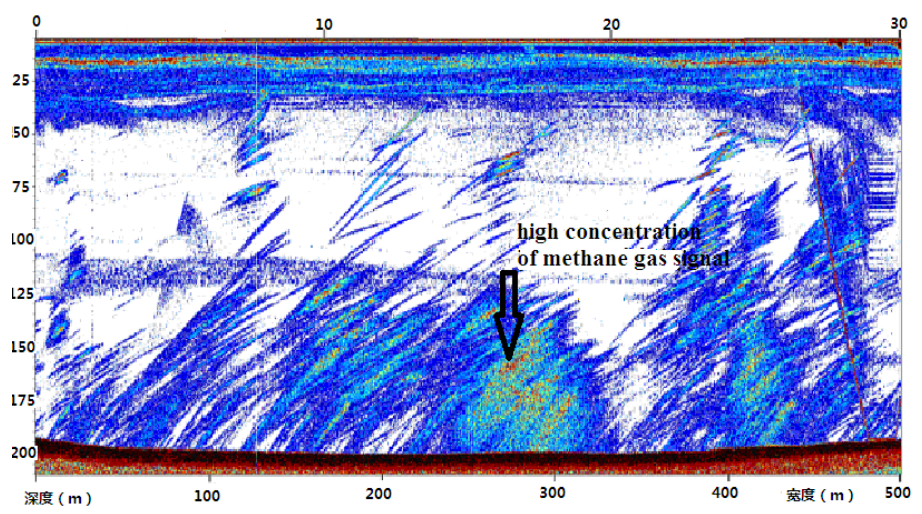

Fig. 7 High Concentration of Methane Gas Signal

SONIC software use dynamic analysis function to show that methane emission of these GF points usually are $0.5 \mathrm{mmol} / \mathrm{s} \sim 0.5 \mathrm{~mol} / \mathrm{s}$ range in large seabed area up to several kilometers.Through software estimation,single bubble rising velocity is 10 to $39 \mathrm{~cm} / \mathrm{sec}$, The average seabed methane flux here is about $5 \mathrm{mmol} / \mathrm{km} 2 \mathrm{~s}$, according to calculate the range of the shallow slope area and the methane emission rate of different regions, the total amount of methane gas leakage in Sakhalin eastern slope is up to 0.2 trillion tons per year.

\section{Conclusion}

Relied on visulization, mathematical statistics and image analysis functions of SONIC software,there are several following conclusions can be made:

By this cruise ,the visulization function of the SONIC software has been proved,it could effectively identify the reisons on the seabed,image the morphology of the gas flare,and give investigators useful information to find gas hydrate.

This cruise surveied amounted to 2300 miles in two weeks, 98 GF were found on the eastern slope of the Sakhalin island by the SONIC software acoustic survey.GF were registered at different depths of the seabed - from 105 up to 1480 meters, but the largest number of GF was registered in the range of depths of $600 \sim 900$ meters.

With dynamic analysis function of SONIC software,it show that methane emission of these GF points usually are $0.5 \mathrm{mmol} / \mathrm{s} \sim 0.5 \mathrm{~mol} / \mathrm{s}$.

Through SONIC software estimation,single bubble rising velocity is 10 to $39 \mathrm{~cm} / \mathrm{sec}$.

The total amount of methane gas leakage in Sakhalin eastern slope is up to 0.2 trillion tons per year.

\section{Acknowledgment}

The project is supported by the International Science\&Technology Cooperation Program Of China (2014DFR60490).

\section{References}

[1]. LUAN Xiwu, Y.Jin, A.Obzhirov, YUE Baojing, et al. Characteristics of shallow gas hydrate in Okhotsk Sea. Science in China Series D: Earth Sciences. Vol. 51(2008) No. 3, p. 415-421.

[2]. R Boswell, TS Collett, et al. Current perspectives on gas hydrate resources. Energy \& Environmental Science s. Vol. 4(2011) No. 4, p. 1206-1215.

[3]. KA Kvenvolden, TD Lorenson, et al. The Global Occurrence of Natural Gas Hydrate. American Geophysical Union. Vol.124(2013) , p. 3-18. 
[4]. P Linga, R Kumar, DL Ju, J Ripmeester, P Englezos, et al. A new apparatus to enhance the rate of gas hydrate formation: Application to capture of carbon dioxide. International Journal of Greenhouse Gas Control. Vol.4(2013) No.4 , p.630-637.

[5]. TD Lorenson, TS Collett, RB Hunter, et al. Gas geochemistry of the Mount Elbert Gas Hydrate Stratigraphic Test Well, Alaska North Slope: Implications for gas hydrate exploration in the Arctic. Marine \& Petroleum Geology. Vol.28 (2011) No.2 , p.343-360.

[6]. BJ Phrampus, MJ Hornbach, et al. Recent changes to the Gulf Stream causing widespread gas hydrate destabilization. Nature. Vol.490(2012) No.7421 , p.527-30.

[7]. E Salehi, A Javaherian, MA Pour, NK Farajkhah, et al. MS ArabaniQuantitative seismic pre-stack analysis of potential gas-hydrate resources in the Makran Accretionary Prism, offshore Iran. Marine \& Petroleum Geology. Vol.48 (2013) , p.160-170.

[8]. [12] L Li, X Lei, X Zhang, Z Sha, et al. Gas hydrate and associated free gas in the Dongsha Area of northern South China Sea. Marine \& Petroleum Geology. Vol.39(2013) No.1 , p.92-101. 